\title{
ANATOMIA DA MADEIRA DE ENTEROLOBIUM GLAZIOVII (BENTH.) MESQUITA ${ }^{1}$
}

\author{
PAULO FERNANDO DOS SANTOS MACHADO ${ }^{2}$ \\ JOSÉ NEWTON CARDOSO MARCHIORI ${ }^{3}$ ANELISE MARTA SIEGLOCH ${ }^{4}$
}

\section{RESUMO}

A madeira de Enterolobium glaziovii é microscopicamente descrita e ilustrada com base em amostra procedente do estado do Espírito Santo, a qual era confundida, inicialmente, com Acacia conferta. A principal diferença em relação ao lenho de Enterolobium contortisiliquum reside na abundância de fibras septadas, as quais apresentam, ainda, paredes mais espessas do que na referida espécie sul-brasileira, facilitando o reconhecimento do parênquima axial em plano transversal.

Palavras-chave: Anatomia da madeira, Enterolobium glaziovii, Fabales, Fabaceae.

\section{ABSTRACT}

[Wood anatomy of Enterolobium glaziovii (Benth.) Mesquita].

The wood of Enterolobium glaziovii is microscopically described and illustrated based on a sample collected in the State of Espírito Santo (Brazil) that was initially misidentified as Acacia conferta. The main difference with respect to Enterolobium contortisiliquum lies in the abundance of septate fibers, which also exhibit thicker walls than the southern Brazilian named species, contributing to the recognition of axial parenchyma in cross section.

Keywords: Enterolobium glaziovii, Fabales, Fabaceae, Wood anatomy.

\section{INTRODUÇÃO}

Em recente pesquisa anatômica com madeiras do antigo gênero Acacia, uma amostra de Acacia conferta coletada no Brasil mostrou-se estruturalmente incompatível à identidade botânica fornecida. O referido binômio, cabe salientar, remete a uma espécie arbustiva de até $4 \mathrm{~m}$ de altura, nativa da Austrália (Nova Gales do Sul, Queensland) e cultivada como ornamental, sobretudo em sua pátria de origem, pelo efeito decorativo dos densos filódios de até $1,5 \mathrm{~cm}$ de comprimento e capítulos globosos de flores amarelas.

1 Recebido em 13-5-2015 e aceito para publicação em 2-9-2015.

2 Engenheiro Florestal, mestrando do Programa de PósGraduação em Engenharia Florestal - UFSM.

3 Engenheiro Florestal, Dr. Professor Titular do Departamento de Ciências Florestais, Universidade Federal de Santa Maria. Bolsista de Produtividade em Pesquisa (CNPq - Brasil).

4 Engenheira Florestal, doutoranda do Programa de PósGraduação em Engenharia Florestal, Universidade Federal de Santa Maria. Bolsista CAPES.
Constatada a discrepância anteriormente resumida, a investigação feita a partir dos dados constantes na ficha de registro do material, juntamente com pesquisa bibliográfica e a busca da respectiva exsicata em herbários do Brasil, comprovou que a amostra de madeira CVRD 242 (Col. J. Spada 107, 30-11-1972) pertence, efetivamente, a Enterolobium glaziovii (Benth.) Mesquita, e que o correspondente material botânico foi examinado pelo autor da espécie, em sua descrição original.

Uma vez comprovado que a espécie botânica foi descrita apenas em 1993 - e que a literatura sobre a mesma, por consequiência, ainda é escassa -, o presente trabalho justifica-se como reforço à valorização dessa essência florestal, e por agregar conhecimento sobre a estrutura do lenho, no gênero botânico a que pertence.

\section{REVISÃO DE LITERATURA}

Nativa no sudeste e nordeste do Brasil, nos estados de Minas Gerais, Rio de Janeiro, Espírito Santo e Bahia, Enterolobium glaziovii (Benth.) Mesquita apresenta estreita afinidade 
com Enterolobium schomburgkii Benth., da qual separa-se, facilmente, pelo fruto lenhoso de epicarpo rugoso, pelas sementes ovais de apenas $1 \mathrm{~cm}$ de comprimento, e pelos ramos e flores totalmente cobertos por indumento ferrugíneo-viloso, entre outros aspectos morfológicos (Mesquita, 1993). No tocante à sinonímia botânica, Corrêa (1926) informa que o binômio Enterolobium lutescens Mart., indicado por Freire Allemão, Saldanha da Gama e Rebouças, entre outros autores, constitui nomen nudum, por carecer de publicação válida.

Árvore de até $30 \mathrm{~m}$ de altura e $18 \mathrm{~cm}$ de DAP, Enterolobium glaziovii apresenta distribuição alopátrica com E. schomburgkii Benth., e distribuição simpátrica com E. monjollo (Vell.) Mart. (Mesquita, 1993). A respeito da madeira, a literatura ainda é carente de maiores detalhes, justificando a realização do presente estudo.

Para o gênero Enterolobium Mart., Metcalfe \& Chalk (1972) reportam: vasos pequenos, principalmente solitários, em múltiplos de 2-3 ou em racemos; placas de perfuração simples; pontoações alternas, pequenas e ornamentadas; parênquima axial vasicêntrico e confluente, com cristais em câmaras no contato com fibras; raios unisseriados ou com até 3 células de largura; e fibras de paredes finas.

Em chave para identificação anatômica do lenho de Leguminosas Mimosoídeas e Cesalpinioídeas argentinas, Cozzo (1951) segrega o gênero Enterolobium pela ausência de estrutura estratificada e de espessamentos espiralados em vasos, aliada à ocorrência de fibras de paredes delgadas, frequentemente "tabicadas" (septadas), e raios 1-3-seriados, compostos, inteiramente, de células procumbentes.

Das madeiras do gênero Enterolobium, a mais investigada é a timbaúva (Enterolobium contortisiliquum (Vell.) Morong), espécie de ampla distribuição geográfica no Brasil e países vizinhos, e para a qual se encontram descrições microscópicas em Bolzon (1993), Marchiori et al. (2009), Mattos et al. (2003) e Tortorelli (1956), entre outros autores.

\section{MATERIAL E MÉTODOS}

O material em estudo consiste na amostra de madeira CRVD 242 (Col. Spada, J., n. 107, 30-11-1972), coletada no município de Linhares, Espírito Santo, e identificada, originalmente, pelo binômio Acacia conferta e o nome comum de "cobi-orelha-de-macaco". Nos capítulos precedentes relatou-se a comprovação da identidade, e que a mesma se trata de Enterolobium glaziovii (Benth.) Mesquita.

Para a confecção de lâminas histológicas foram extraídos três corpos-de-prova ( $1 \times 2 \times 3$ $\mathrm{cm}$ ) da amostra de lenho, orientados para a obtenção de cortes anatômicos nos planos transversal, longitudinal radial e longitudinal tangencial. Do fragmento restante foram extraídos palitinhos, com vistas à maceração.

$\mathrm{O}$ preparo de lâminas de cortes anatômicos seguiu a metodologia descrita em Burger \& Richter (1991) e, no caso do macerado, o método de Jeffrey (Freund, 1970). Os cortes anatômicos foram tingidos com acridina-vermelha, crisoidina e azul-de-astra (Dujardin, 1964); o macerado, apenas com safranina. Usou-se Entellan na montagem das lâminas.

A descrição anatômica baseou-se nas recomendações do IAWA Committee (Wheeler et al., 1989). No caso da percentagem dos tecidos foram realizadas 600 determinações ao acaso, com o auxílio de contador de células, conforme proposto por Marchiori (1980). A abundância de poros foi obtida a partir de um quadrado de área conhecida, superposto a fotomicrografias de seções transversais da madeira.

As medições foram realizadas em microscópio Carl Zeiss, no Laboratório de Anatomia da Madeira da Universidade Federal de Santa Maria. Na citação dos caracteres quantitativos, os números entre parênteses correspondem aos valores mínimo e máximo observados; o valor que acompanha a média é o desvio padrão. As fotomicrografias foram tomadas em aparelho Leica DM 1000, equipado com câmera digital Olympus Camedia CX 40, no Laboratório de Anatomia da Madeira do CESNORS/UFSM. 


\section{DESCRIÇÃO MICROSCÓPICA}

Anéis de crescimento: fracamente distintos, delimitados por 1-3 fileiras de fibras radialmente estreitas, pelo parênquima marginal associado a poros de pequeno diâmetro, e pelo tênue alargamento de raios no limite do anel.

Vasos: escassos (5 \pm 2 (3-9) poros $/ \mathrm{mm}^{2}$ ), ocupando $13 \pm 3 \%$ do volume da madeira. Porosidade difusa. Poros solitários $(73 \%)$, em múltiplos radiais de 2-5 (15\%), e em múltiplos racemiformes (12\%); circulares ou ovais (186 $\pm 30(133-255) \mu \mathrm{m})$ e de paredes finas até espessas $(9 \pm 2(2,5-13) \mu \mathrm{m})$ (Figura 3A,B). Elementos vasculares médios (425 \pm 118 (230-640) $\mu \mathrm{m})$, com placas de perfuração simples, oblíquas ou transversais ao vaso. Apêndices curtos $(39 \pm 25(10-100) \mu \mathrm{m})$, geralmente em uma extremidade. Pontoações intervasculares pequenas $(6,0 \pm 0,9(5,2-7,2) \mu \mathrm{m})$ e ornamentadas, alternas, circulares, com abertura em fenda inclusa, por vezes coalescente (Figura 3F). Pontoações raio-vasculares, semelhantes às intervasculares, embora menores $(5,0 \pm 0,6(4-6) \mu \mathrm{m})$. Espessamentos espiralados, ausentes. Conteúdos, presentes.

Parênquima axial: representando $30 \pm 6 \%$ do volume da madeira; em arranjo vasicêntrico e diagonal-confluente, além de apotraqueal marginal. Conteúdo, presente em células radiais (Figura 3 A,B). Séries parenquimáticas de $553 \pm 118$ (300-745) $\mu \mathrm{m}$ de altura, com 3,8 \pm 1,2 (2-6) células (Figura 3F). Cristais romboédricos, em séries de 2-30 cristais (Figura 3A,B).

Raios: numerosos $(5 \pm 0,9(3-8) / \mathrm{mm})$, ocupando $14 \pm 1,8 \%$ do volume da madeira; homogêneos, compostos inteiramente de células procumbentes, com $3(2-5)$ células e $33 \pm 11$ (18-55) $\mu \mathrm{m}$ de largura (Figura 3E,F). Os multisseriados, de $327 \pm 124$ (100-550) $\mu \mathrm{m}$ e 631 células de altura. Os unisseriados, de $110 \pm$ 35 (40-200) $\mu \mathrm{m}$ e 3-13 células de altura. Conteúdos, escassos. Raios agregados e fusionados, presentes. Células envolventes, células radiais de paredes disjuntas e células perfuradas, ausentes.

Fibras: libriformes, septadas, de $1390 \pm 185$ (1030-1670) $\mu \mathrm{m}$ de comprimento, com $17 \pm 3$ (12-23) $\mu \mathrm{m}$ de largura e paredes medianamente espessas $4 \pm 1,3(2,5-7,5) \mu \mathrm{m}$, ocupando $43 \pm 5$ $\%$ do volume da madeira (Figura 3B). Fibras gelatinosas, escassas; espessamentos espiralados e traqueídeos, ausentes.

Outros caracteres: variantes cambiais, tubos laticíferos e taniníferos, canais intercelulares, células oleíferas, células mucilaginosas, estratificação e máculas medulares, ausentes. Cristais, presentes.

\section{ANÁLISE ANATÔMICA}

A madeira de Enterolobium glaziovii reúne o conjunto de caracteres anatômicos típico das Fabaceae Mimosoideae: placas de perfuração simples; pontoações intervasculares alternas e ornamentadas; parênquima paratraqueal; fibras libriformes; raios homogêneos; ausência de estratificação; e abundantes cristais em câmaras, na periferia do parênquima axial.

Comparada a Enterolobium contortisiliquum, a espécie em estudo distingue-se pelas fibras de paredes medianamente espessas, caráter que lhe confere, muito provavelmente, uma maior massa específica e resistência mecânica. A parede mais espessa das fibras, por sua vez, ressalta o contraste entre esse tecido e o parênquima axial, facilitando o reconhecimento dos padrões paratraqueal vasicêntrico, diagonal-confluente e apotraqueal marginal, muito conspícuos em Enterolobium glaziovii.

A presença conspícua de septos nas fibras da espécie em estudo contrasta com o descrito por Marchiori et al. (2009), Mattos et al. (2003) e Muñiz (1993) para E. contortisiliquum, autores que não assinalaram a presença do caráter no lenho da referida espécie sul-brasileira. Cabe ressaltar, entretanto, que Tortorelli (1956) refere fibras libriformes para a mesma, e "con frecuencia tabicadas". 

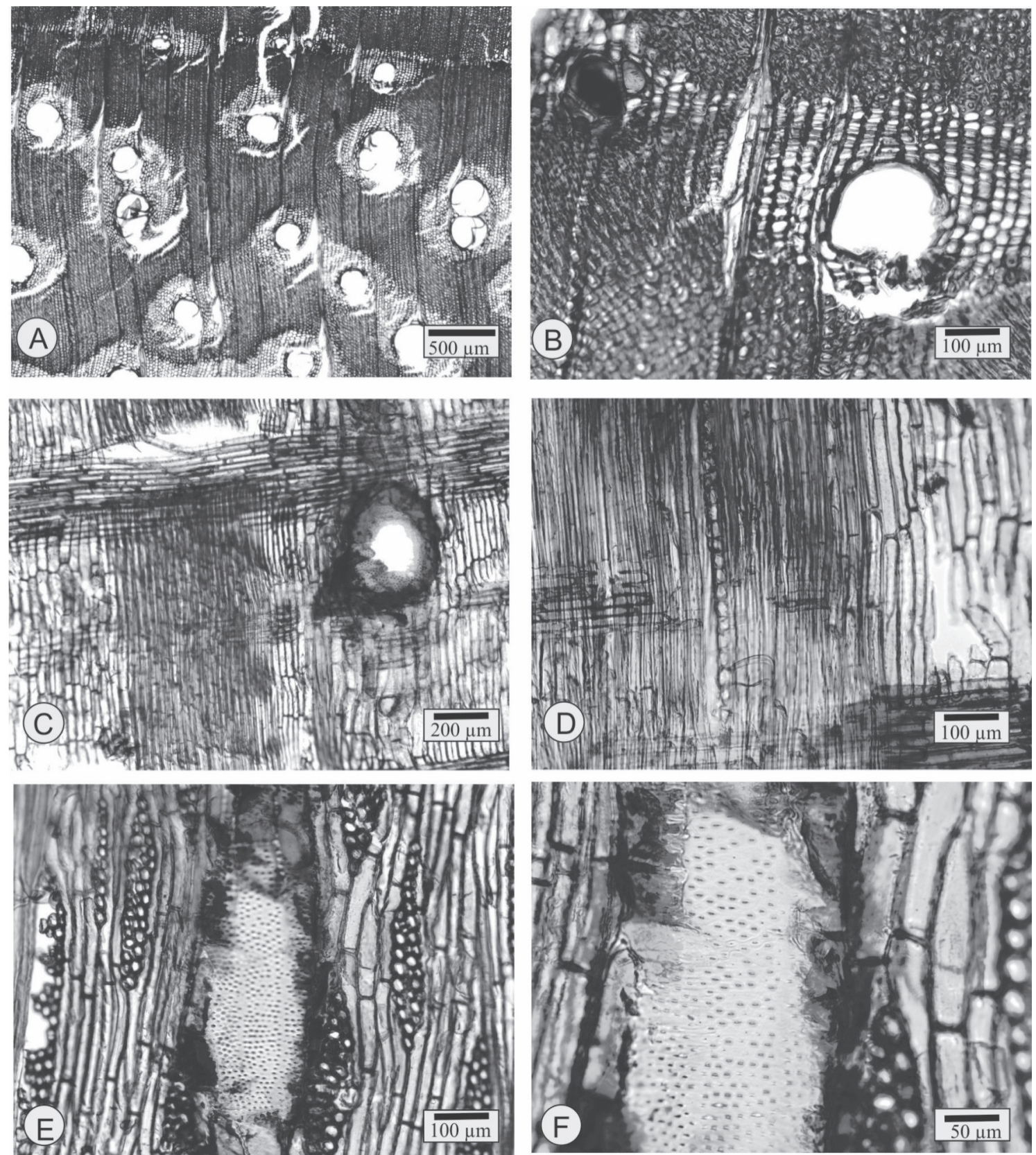

FIGURA 1 - Fotomicrografias do lenho de Enterolobium glaziovii. A - Porosidade difusa, poros solitários, em múltiplos radiais, e parênquima paratraqueal confluente e marginal (seção transversal). B - Anel de crescimento marcado por parênquima marginal, 1-3 fileiras de fibras radialmente estreitas e tênue alargamento de raios (seção transversal). C - Raio composto inteiramente de células procumbentes e parênquima axial abundante (seção radial). D - Raio de células procumbentes, cristais em câmaras, parênquima axial seriado e fibras septadas (seção radial). E - Raios uni e multisseriados, e parênquima axial (seção tangencial). F - Elemento vascular com pontoações intervasculares ornamentadas, raios multisseriados e parênquima axial abundante (seção tangencial). 
Enterolobium glaziovii separa-se muito facilmente de E. contortisiliquum por seus raios mais largos, de até 5 células de largura, ao passo que na segunda predominam os bi e unisseriados, com raros trisseriados.

\section{REFERÊNCIAS BIBLIOGRÁFICAS}

BURGER, L.M.; RICHTER, H.G. Anatomia da Madeira. São Paulo: Ed. Nobel, 1991. 154 p.

CORRÊA, M.P. Dicionário de plantas úteis do Brasil e das exóticas cultivadas. Rio de Janeiro: Ministério da Agricultura : Instituto Brasileiro de Desenvolvimento Florestal, 1984. v. 3, p. 26.

COZZO, D. Anatomia del leño secundario de las Leguminosas Mimosoideas y Cesalpinioideas argentinas silvestres y cultivadas. Revista del Instituto Nacional de Investigación de las Ciencias Naturales, Buenos Aires, 1951, v. 2 , n. 2, p. 63-146.

DUJARDIN, E.P. Eine neue Holz-Zellulosenfaerbung. Mikrokosmos, n. 53, p. 94, 1964.

FREUND, H. Handbuch der Mikroskopie in der Technik. Frankfurt: Umsham Verlag, 1970. 375 p.

MARCHIORI, J.N.C. Estudo anatômico do xilema secundário e da casca de algumas espécies dos gêneros Acacia e Mimosa, nativas no estado do Rio Grande do Sul. Dissertação (Mestrado em
Engenharia Florestal). Curitiba: Universidade Federal do Paraná, 1980. 186 f.

MARCHIORI, J.N.C.; MUÑIZ, G.I.B. de; SANTOS, S.R. dos. Madeiras do Rio Grande do Sul. 1 Descrição microscópica de 33 espécies nativas. Santa Maria: [s.n.], 2009. 80 p.

MATTOS, P.P. de; TEIXEIRA, L.L.; SEITZ, R.A.; SALIS, S.M. de; BOTOSSO, P.C. Anatomia de madeiras do Pantanal matogrossense (Características microscópicas). Colombo: Embrapa, 2003. 182 p.

MESQUITA, A. de L. Enterolobium glaziovii (Benth.) Mesquita, comb. nov. et "status novum" para as regiões sudeste e nordeste do Brasil. Acta Bot. Bras., v, 7, n. 2, p. 17-23, 1993.

MUÑIZ, G.I.B. de. Anatomia da madeira de espécies arbóreas da Floresta Estacional Semidecidual de Misiones, Argentina. Curitiba: Universidade Federal do Paraná, 1993. 152 f. Tese (Concurso de Professor Titular) - Universidade Federal do Paraná.

RECORD, S.J.; HESS, R.W. Timbers of the New World. New Haven: Yale Univ. Press, 1949. 640 p.

TORTORELLI, L.A. Maderas y bosques argentinos. Buenos Aires: Ed. ACME, 1956. 910 p.

WHEELER, E.A.; BAAS, P.; GASSON, P.E. IAWA list of microscopic features for hardwood identification. IAWA Bulletin, v. 10, n. 3, p. 218359, 1989. 